\title{
Calculation of Dose in Healthy Organs, during Radiotherapy 4-Field Box 3D Conformal for Prostate Cancer, Simulation of the Linac 2300, Radiotherapy Room and MAX Phantom
}

\author{
Jardel L. Thalhofer ${ }^{1}$, Wilson F. Rebello ${ }^{2}$, Samanda A. Correa ${ }^{3}$, Ademir X. Silva ${ }^{1}$, \\ Edmilson M. Souza ${ }^{4}$, Delano V. Batista ${ }^{5}$ \\ ${ }^{1}$ Programa de Engenharia Nuclear, Universidade Federal do Rio de Janeiro, Rio de Janeiro, Brazil \\ ${ }^{2}$ Seção de Engenharia Nuclear, Instituto Militar de Engenharia, Rio de Janeiro, Brazil \\ ${ }^{3}$ Comissão Nacional de Energia Nuclear, Rio de Janeiro, Brazil \\ ${ }^{4}$ Centro Universitário Estadual da Zona Oeste, Rio de Janeiro, Brazil \\ ${ }^{5}$ Instituto Nacional de Câncer, Rio de Janeiro, Brazil \\ Email: jardellt@yahoo.com.br
}

Received November 22, 2012; revised February 1, 2013; accepted March 15, 2013

Copyright (C) 2013 Jardel L. Thalhofer et al. This is an open access article distributed under the Creative Commons Attribution License, which permits unrestricted use, distribution, and reproduction in any medium, provided the original work is properly cited.

\begin{abstract}
In men, prostate cancer is one of the most frequent types, and radiotherapy is adopted as a form of treatment. Although there are efforts to minimize the dose in the healthy organ and tissues adjacent to the tumor during radiotherapy, these organs are affected by the secondary scattered and leakage radiation originating from the therapeutic beam and these doses deposited in the healthy organs, can induce the appearance of new focal points of cancer. The aim of this study is to calculate the equivalent and effective doses, due to photons and neutrons, in healthy organs of a patient submitted to radiotherapy treatment for prostate cancer. Computed simulation of radiotherapy treatment for prostate cancer was used to perform the dose calculations, adopting the treatment protocol used at INCA (Brazilian National Cancer Institute). The MCNPX code was employed in the simulation radiation transport while the male voxel MAX phantom was used to represent the patient's human anatomy. The results obtained in this study indicate that the organs close to the irradiated region are predominantly affected by the dose due to photons, with an impact on organs from different systems of the body, such as the bladder, colon, and testicles, besides bone structures such as the femur, pelvis and spinal column. The results obtained from the doses deposited due to neutrons suggest that tibia and fibula, mandible, cranium, brain and thyroid, had the highest dose deposited due to neutrons in relation to photons. The result obtained from the effective dose was $31.47 \mathrm{mSv}$ due to photons, while the dose due to neutrons was $0.42 \mathrm{mSv}$. Note that the effective dose due to photons is significantly higher than the effective dose due to neutrons. The values calculated in this study were compared with the experimental values obtained in the literature, presenting reasonable concordance. Additionally, as described in the literature, it was verified that the dose due to photons decreases considerably with the increase in the distance of the target organ, while the dose due to neutrons is distributed homogeneously in the organs. It is concluded that the contribution of neutrons to the appearance of secondary cancers is more relevant in the organs furthest from the target volume, and that organs close to the tumor, are affected predominantly by the dose due to photons.
\end{abstract}

Keywords: Radiotherapy; Prostate; MCNPX; MAX and Linac

\section{Introduction}

Cancer is the uncontrolled growth and spread of cells. It can affect almost any part of the body. The growths often invade surrounding tissue and can metastasize to distant sites [1]. According to the National Cancer Institute

${ }^{*}$ Corresponding author.
(INCA), it is estimated that in Brazil alone, 60,180 new cases of prostate cancer will appear in the year 2012 [2]. Men diagnosed in the initial stage can achieve greater success in the treatment, as there are various types of treatment to be adopted, such as prostatectomy, chemotherapy and radiotherapy (teletherapy, and bractherapy) [3]. 
One of the procedures used most often in prostate cancer treatment, is radiotherapy, in the form of teletherapy. This treatment is based on the use of radiation, through a photon beam collimated according to the size and volume to be treated. This treatment aims to deliver the maximum dose of radiation to the tumor volume, minimizing the dose in the adjacent healthy organs and tissues [4]. Nowadays one of the equipment used most often in these procedures is the Linear Accelerator.

Although there are efforts to minimize the dose in the healthy organ and tissues adjacent to the tumor during radiotherapy, these organs are affected by the secondary scattered and leakage radiation originating from the therapeutic beam $[3,5,6]$. This fact associated with the increase in the life expectancy of the world population has provoked an increase in the risk of developing secondary cancers $[2,7]$. Some studies carried out demonstrated, for example, that patients submitted to radiotherapy for prostate cancer can develop several kinds of secondary cancers [6] especially in the rectum and in the bladder [8-11]. Although there are studies that demonstrate an increase in the risk of appearance of secondary cancers due to the prostate cancer radiotherapy treatment, as yet there are few studies that estimate the absorbed dose in the organs and tissues adjacent to the tumor during treatment.

Considering the foregoing, the objective of this study is to estimate the equivalent dose and effective dose during treatment for prostate cancer, due to photons and neutrons using simulations with the Monte Carlo MCNPX code. For the performance of the study, we will consider the treatment protocol used at the National Cancer Institute which is the center of reference in cancer treatment in Brazil. With the purpose of making the calulations more realistic, the head of the Varian 2300CD linear accelerator and the radiotherapy room will be considered in the simulation. The male voxel MAX will be used to represent the patient's body [12].

\section{Computer Modeling}

\subsection{MCNPX Code}

Version 2.5.0 of the Monte Carlo MCNPX code was used in this study to simulate radiation transport. MCNPX enables the simulation of several types of radiation, such as photons, electrons and neutrons. Moreover, it is able to simulate varied types of interaction (incoherent and coherent scattering, fluorescent emission after photoelectric absorption, pair production with local emission of annihilation photons and bremsstrahlung, production of photoneutrons) $[13,14]$, and the secondary radiations arising from the interactions of a type of radiation with a particular material. In this study the types of radiation of interest simulated were photons, electrons and neutrons.

The production of photoneutrons occurs when highenergy photons, above $6.7 \mathrm{MeV}[15,16]$, interact with structures of the head of the linear accelerator. Consequently, these neutrons contribute to the deposition of an additional dose in patients submitted to treatments with energy beams from 10 to $18 \mathrm{MeV}$. Therefore, the simulation of photoneutrons was necessary in view of the fact that there is contamination of the treatment environment, originating from the interaction of high-energy photons with materials present in the collimator jaws and Multileaf Collimator (MLC), in the head of the Varian 2300CD Linear Accelerator, mainly tungsten.

\subsection{System Modeling}

The head of the Varian 2300CD Linear Accelerator and the radiotherapy room used in this study were developed and validated previously by our research group [17].

Figure 1 presents the room and the accelerator head model considered in this study. To represent the patient during the simulations, the MAX phantom without the forearm was inserted inside the radiotherapy room, with the prostate in the isocenter position at a distance of 100 $\mathrm{cm}$ from the focal point of the accelerator. In this study the forearm of the MAX phantom was removed to prevent it from being an attenuating structure in the projections of incidence of the lateral therapeutic beams at the angles of $90^{\circ}$ and $270^{\circ}$ during the treatment simulation.

\subsection{Treatment Protocol}

The treatment protocol used in this study is the same adopted by INCA, one of the main centers of reference in cancer treatment in Brazil. Various types of cancer are treated at INCA, including prostate cancer, the focus of this study.

Four gantry tilt angles are used in the treatment protocol for prostate cancer, as described in Table 1. The prostate is positioned at the isocenter $(0,0,0)$, located at a source-surface distance of $100 \mathrm{~cm}$, with Linac 2300 operating at $18 \mathrm{MV}$, thus producing photoneutrons. The usual therapeutic dose adopted in the treatment is $74 \mathrm{~Gy}$, with dose segmentation and variation of the gantry tilt angle (2 anteroposterior and 2 lateral fields). These tilt angles were determined according to the anatomical positioning of the organs.

The organs have irregular formats and varied sizes, for which reason we use different field sizes. These field sizes are determined by the opening of the collimator jaws and MLC, varying according to the gantry tilt angle, whereas the values of field sizes used are presented in Table 1. In addition, other reference centers use a similar treatment protocol, adopting the same gantry tilt angles, as described in the literature [18]. 


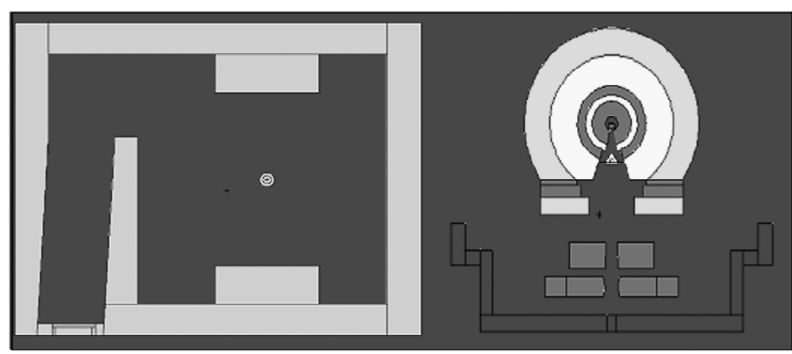

Figure 1. Visualization of the radiotherapy room and simulated head [16].

Table 1. Ratio of the field size of the useful beam to the gantry tilt angle, according to the treatment protocol of INCA for prostate cancer.

\begin{tabular}{ccc}
\hline Angles & Jaws $\left.\mathbf{( c m}^{\mathbf{2}}\right)$ & MLC $\left.\mathbf{( c m}^{\mathbf{2}}\right)$ \\
\hline $0^{\circ}$ & $10 \times 10$ & $9 \times 9$ \\
$90^{\circ}$ & $8 \times 10$ & $7 \times 9$ \\
$180^{\circ}$ & $10 \times 10$ & $9 \times 9$ \\
$270^{\circ}$ & $8 \times 10$ & $7 \times 9$ \\
\hline
\end{tabular}

\subsection{Calculations of the Doses Due to Photons and Neutrons}

In this study we analyzed the contributions of dose due to photons and due to neutrons separately for the four gantry tilt angles.

\subsubsection{Simulation of Radiotherapy Treatment for Prostate Cancer, in the Calculation of Dose Due to Photons}

To estimate the absorbed dose in the patient's organs due to photons, the energy deposited by radiation in the organs and tissues of the MAX voxel phantom was obtained using MCNPX. It is possible to obtain the energy deposited in a set of voxels that form an organ or tissue of the phantom. The obtainment of the absorbed dose was achieved by dividing the energy deposited in the organ or tissue by its respective mass value (m), according to the equations below [19-21]

$$
\begin{aligned}
& \mathrm{D}_{\mathrm{T}}(\text { rads })=\frac{{ }^{*} \mathrm{~F} 8(\mathrm{MeV})}{\mathrm{m}} \\
& \left(1.602 \times 10^{-6} \mathrm{erg} / \mathrm{MeV}\right)\left(\frac{1}{100 \mathrm{erg} / \mathrm{g} / \mathrm{rad}}\right) \\
& \mathrm{D}_{\mathrm{T}}(\text { rads })=\frac{{ }^{*} \mathrm{~F} 8}{\mathrm{~m}} 1.602 \times 10^{-8} \\
& \mathrm{D}_{\mathrm{T}}(\mathrm{Gy})=\frac{{ }^{*} \mathrm{~F} 8}{\mathrm{~m}} 1.602 \times 10^{-10}
\end{aligned}
$$

where $m$ is the mass of the organ or tissue for which we wish to estimate the absorbed dose.

\subsubsection{Simulation of Radiotherapy Treatment for Prostate Cancer, in the Calculation of Dose Due to Neutrons}

To estimate the absorbed dose in the patient's organs due to neutrons, the energy deposited by radiation in the organs and tissues of the MAX voxel phantoms was obtained using the MCNPX. It is possible to obtain the energy deposited by unit of mass in a set of voxels that form an organ or tissue of the phantom, thus providing the deposited dose. To obtain the equivalent dose in the $\mathrm{Sv}$ unit, the result obtained through MCNPX (MeV/g) was multiplied by the factor equal to $1.602 \times 10^{-10}$.

\subsubsection{Calculation of the Equivalent Dose Due to Photons and Neutrons}

The radiation weighting factors of ICRP 103 [22] were considered in calculating the equivalent dose due to photons and neutrons.

Considering that the weighting factor due to photons is equal to one (1), the calculation of the equivalent dose due to photons was calculated by multiplying the absorbed dose in an organ or tissue by one (1). To calculate the equivalent dose due to neutrons we considered the weighting factor curve presented in Figure 2.

As can be seen in Figure 2, the radiation weighting factors due to neutrons vary with the energy. Thus, each absorbed dose obtained for each energy interval was multiplied by the corresponding $\mathrm{w}_{\mathrm{R}}$. At the end, adding up all the doses separated by interval, already weighted by the $w_{R}$, we obtain the equivalent dose for neutrons by angle in the organ in question.

In this study the equivalent doses due to photons and neutrons were calculated for each treatment angle. To obtain the total equivalent dose for each type of radiation the dose values of the four treatment angles were added together.

All the dose values provided in this study were estimated considering mSv per unit Gy of absorbed dose in

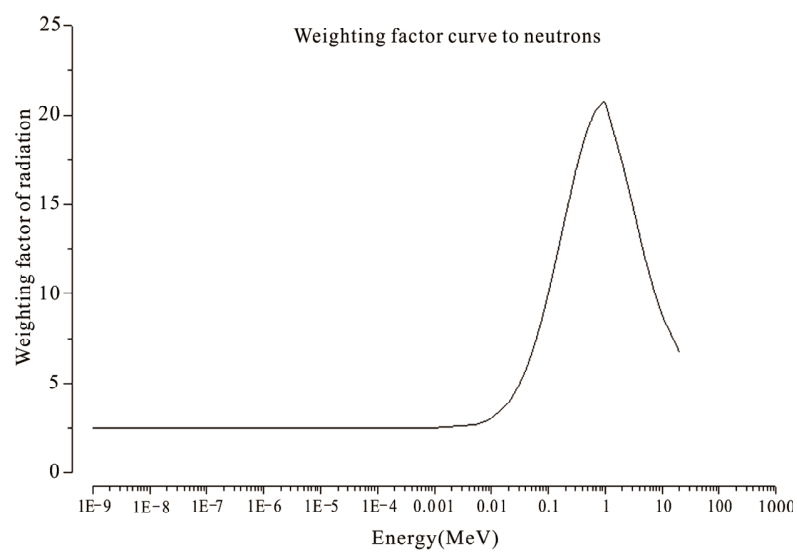

Figure 2. Radiation weighting values used for neutrons considering ICRP 103 [21]. 
the prostate due to photons, following the standard used in the literature [23].

\subsubsection{Effective Dose}

The calculation of the effective dose was performed considering the tissue radio sensitivity factors recommended by ICRP 103 [22].

\section{Results and Discussion}

\subsection{Equivalent dose}

The calculated values of equivalent dose $(\mathrm{H})$ for photons and neutrons will be presented separately in this study, with detailing of the values by angle and total.

\subsubsection{Equivalent Dose Due to Photons}

Table 2 and Figure 3 present the values of equivalent dose due to photons for each treatment angle and for the complete treatment. The dose values presented were calculated considering the absorbed dose in the prostate due to photons of $1 \mathrm{~Gy}$.

Table 2 shows that the total equivalent dose deposited in the organs varied from 723.79 to $0.10 \mathrm{mSv} / \mathrm{Gy}$. This variation verified in the equivalent dose due to photons is attributed to the distance from the healthy organs to the treated volume (prostate region), Figure 3. It was also verified that the rectum was the organ that received the highest dose, $723.39 \mathrm{mSv} / \mathrm{Gy}$, and that the irradiation at the angle of $180^{\circ}$, contributed with about $30.31 \%$ of the dose value. The bladder, another organ close to the prostate, also presented considerable values of equivalent dose, while the anteroposterior and posteroanterior angles $\left(0^{\circ}\right.$ and $\left.180^{\circ}\right)$ contributed most to the dose, corresponding to $62.36 \%$. It is also interesting to note that for the femur, the irradiations at the lateral angles $\left(90^{\circ}\right.$ and $270^{\circ}$ ), contributed predominantly (about $99.11 \%$ ) to the dose values presented. This is expected since at the lateral angles the femoral head anatomically precedes the prostate. Moreover, it was observed that the pelvis presented significant dose values (214.49 mSv/Gy).

Organs such as the colon and testicles also received considerable dose values yet lower than those of the organs closer to the irradiation region. It was also verified that the dose values were lower for the organs located in the extremity of the body, with the brain and thyroid having presented the lowest values of equivalent dose due to photons, Figure 3.

\subsubsection{Equivalent Dose Due to Neutrons}

Table 3 presents the values of the equivalent doses due to neutrons. And Figure 4 graphically demonstrates the values of some organs.

The values of dose due to neutrons were calculated considering $1 \mathrm{~Gy}$ of absorbed dose in the prostate due to photons. Comparing the equivalent dose values presented in Tables 2 and 3, it can be seen that the total equivalent dose due to neutrons is significantly lower than the equivalent dose due to photons. Furthermore, through Figures $\mathbf{3}$ and $\mathbf{4}$ we can observe that the equivalent dose varies according to the gantry tilt, and we also note a different behavior in relation to the distribution of values of equivalent dose due to photons and neutrons. The values of equivalent dose due to neutrons did not decrease with the increase in the distance between the organ and the treated volume. The tibia and fibula received the total dose of $2.21 \mathrm{mSv} / \mathrm{Gy}$, a value approximately 10 times greater than the equivalent dose due to photons. It can also be seen that the mandible and cranium received 1.60 and $0.83 \mathrm{mSv} / \mathrm{Gy}$, approximately 16 and 5 times greater than the total dose due to photons, respectively. The

Table 2. Equivalent dose due to photons, for each treatment angle and total.

\begin{tabular}{|c|c|c|c|c|c|}
\hline \multirow{2}{*}{ ORGANS } & \multicolumn{4}{|c|}{ Equivalent Dose (mSv/Gy) } & \multirow{2}{*}{ H-total } \\
\hline & $0^{\circ}$ & $90^{\circ}$ & $180^{\circ}$ & $270^{\circ}$ & \\
\hline Rectum & 177.56 & 132.10 & 219.37 & 194.77 & 723.79 \\
\hline Bladder & 109.06 & 55.43 & 98.21 & 145.46 & 408.16 \\
\hline Femur & 1.72 & 144.63 & 1.77 & 243.96 & 392.09 \\
\hline Pelvis & 34.78 & 47.02 & 28.91 & 103.77 & 214.49 \\
\hline Colon & 17.53 & 13.61 & 21.52 & 19.81 & 72.46 \\
\hline Remainder & 7.00 & 5.85 & 7.28 & 16.46 & 36.59 \\
\hline Testes & 7.13 & 2.29 & 7.38 & 5.39 & 22.18 \\
\hline Spine & 2.02 & 0.64 & 2.80 & 0.75 & 6.21 \\
\hline $\begin{array}{l}\text { Large } \\
\text { Intestine }\end{array}$ & 0.60 & 1.07 & 0.58 & 1.29 & 3.53 \\
\hline $\begin{array}{c}\text { Small } \\
\text { Intestine }\end{array}$ & 0.40 & 0.67 & 0.52 & 1.05 & 2.64 \\
\hline Kidneys & 0.16 & 0.38 & 0.18 & 0.34 & 1.06 \\
\hline Pancreas & 0.15 & 0.13 & 0.14 & 0.32 & 0.75 \\
\hline Liver & 0.12 & 0.24 & 0.11 & 0.24 & 0.71 \\
\hline Spleen & 0.08 & 0.26 & 0.11 & 0.24 & 0.69 \\
\hline Humerus & 0.06 & 0.32 & 0.08 & 0.22 & 0.67 \\
\hline Stomach & 0.11 & 0.23 & 0.09 & 0.21 & 0.63 \\
\hline Adrenals & 0.11 & 0.06 & 0.11 & 0.26 & 0.55 \\
\hline Lungs & 0.08 & 0.16 & 0.08 & 0.12 & 0.44 \\
\hline Esophagus & 0.07 & 0.19 & 0.07 & 0.08 & 0.41 \\
\hline Thymus & 0.09 & 0.06 & 0.07 & 0.11 & 0.33 \\
\hline $\begin{array}{l}\text { Tibia and } \\
\text { Fibula }\end{array}$ & 0.05 & 0.04 & 0.04 & 0.07 & 0.20 \\
\hline Trachea & 0.04 & 0.10 & 0.02 & 0.05 & 0.22 \\
\hline Thyroid & 0.04 & 0.04 & 0.03 & 0.06 & 0.18 \\
\hline Brain & 0.02 & 0.09 & 0.02 & 0.03 & 0.16 \\
\hline Skull & 0.02 & 0.07 & 0.03 & 0.03 & 0.15 \\
\hline Mandible & 0.02 & 0.04 & 0.01 & 0.02 & 0.10 \\
\hline
\end{tabular}




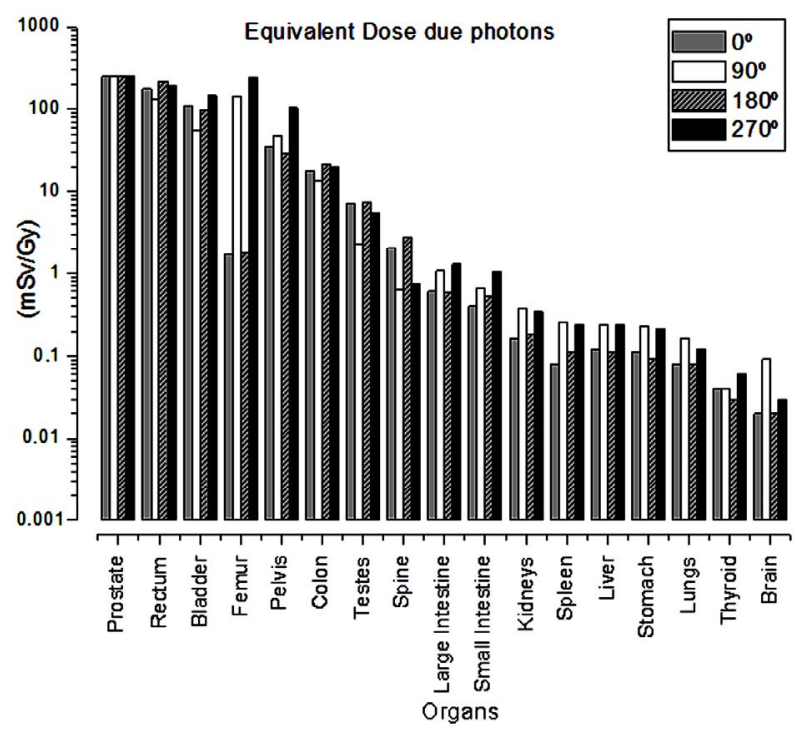

Figure 3. Equivalent dose due to photons, calculated for each treatment angle.

brain and the thyroid also presented higher values of equivalent dose due to neutrons when compared with the values of dose due to photons. Moreover, it is interesting to note that nearby organs and bone structures were also affected by the deposition of neutrons, not receiving such high doses as that of photons.

In analyzing Table 3, also note that the equivalent dose in the lens of the eyes due to neutrons is not negligible (about $0.58 \mathrm{mSv} / \mathrm{Gy}$ ), different from that observed when analyzing the dose in this organ due to photons.

Figure 5 contains a comparison of the total equivalent dose deposited due to photons and to neutrons. Through this figure it can be seen that some bone structures and some organs, such as the brain, thyroid were the most affected by the dose due to neutrons in relation to photons. We also noted a more homogeneous dose deposition due to neutrons, when compared with the distribution of equivalent dose due to photons.

\subsubsection{Comparison of Results Obtained with Those from the Literature}

The results obtained in this study were compared with those obtained experimentally by Howell [23]. This comparison is presented in Table 4.

Table 4 shows us that the equivalent dose values obtained in this study presented behaviors similar to those obtained by Howell [23]. The values of equivalent dose in the bladder, colon, testicles, liver, stomach and lung are higher due to photons, while the values of equivalent dose in the thyroid are higher due to neutrons.

As regards the equivalent dose values, it can be seen that, although the values obtained in both studies present the same order of magnitude, there isn't a difference in terms of magnitude. This difference can be explained due to the dosimetry point defined experimentally by Howell [23]. Experimentally the absorbed dose is calculated specifically using thermo luminescent dosimeters, and not in the organ as a whole (mean value deposited in the organ or tissue) as is the case in the simulation. Considering that the dose varies specifically inside the organ according to its proximity to the treated volume, it is concluded that this may be the probable cause of the difference between the values found in this study and obtained experimentally by Howell [23].

Table 3. Equivalent dose due to neutrons, for each treatment angle and total.

\begin{tabular}{|c|c|c|c|c|c|}
\hline \multirow{2}{*}{ ORGANS } & \multicolumn{4}{|c|}{ Equivalent Dose (mSv/Gy) } & \multirow{2}{*}{ H-total } \\
\hline & $0^{\circ}$ & $90^{\circ}$ & $180^{\circ}$ & $270^{\circ}$ & \\
\hline $\begin{array}{l}\text { Tibia and } \\
\text { Fibula }\end{array}$ & 0.28 & 1.39 & 0.16 & 0.37 & 2.21 \\
\hline Mandible & 0.31 & 1.00 & 0.03 & 0.26 & 1.60 \\
\hline Femur & 0.09 & 0.92 & 0.09 & 0.44 & 1.54 \\
\hline Remainder & 0.16 & 0.69 & 0.20 & 0.24 & 1.29 \\
\hline Testes & 0.49 & 0.48 & 0.05 & 0.11 & 1.13 \\
\hline Skull & 0.05 & 0.57 & 0.10 & 0.12 & 0.83 \\
\hline Rectum & 0.13 & 0.15 & 0.38 & 0.09 & 0.75 \\
\hline Pelvis & 0.13 & 0.30 & 0.10 & 0.15 & 0.68 \\
\hline Lens of Eyes & 0.12 & 0.41 & 0.00 & 0.05 & 0.58 \\
\hline Brain & 0.02 & 0.29 & 0.07 & 0.08 & 0.46 \\
\hline $\begin{array}{l}\text { Large } \\
\text { Intestine }\end{array}$ & 0.03 & 0.01 & 0.35 & 0.06 & 0.45 \\
\hline $\begin{array}{c}\text { Small } \\
\text { Intestine }\end{array}$ & 0.13 & 0.09 & 0.03 & 0.14 & 0.39 \\
\hline Humerus & 0.04 & 0.20 & 0.03 & 0.07 & 0.34 \\
\hline Bladder & 0.23 & 0.04 & 0.01 & 0.05 & 0.33 \\
\hline Colon & 0.09 & 0.16 & 0.03 & 0.04 & 0.32 \\
\hline Thyroid & 0.18 & 0.03 & 0.04 & 0.05 & 0.31 \\
\hline Esophagus & 0.06 & 0.11 & 0.07 & 0.05 & 0.30 \\
\hline Spleen & 0.04 & 0.05 & 0.08 & 0.11 & 0.28 \\
\hline Spine & 0.04 & 0.11 & 0.07 & 0.05 & 0.27 \\
\hline Stomach & 0.08 & 0.03 & 0.03 & 0.12 & 0.26 \\
\hline Pancreas & 0.07 & 0.05 & 0.03 & 0.06 & 0.22 \\
\hline Trachea & 0.09 & 0.07 & 0.01 & 0.03 & 0.20 \\
\hline Thymus & 0.09 & 0.06 & 0.01 & 0.01 & 0.18 \\
\hline Liver & 0.04 & 0.09 & 0.02 & 0.02 & 0.17 \\
\hline Lungs & 0.04 & 0.06 & 0.02 & 0.03 & 0.14 \\
\hline Kidneys & 0.01 & 0.04 & 0.02 & 0.02 & 0.08 \\
\hline
\end{tabular}


Table 4. Comparison between the equivalent dose values obtained (photons-P and neutrons-N) in this study and obtained experimentally by Howell et al. (2006).

\begin{tabular}{|c|c|c|c|c|c|c|}
\hline \multirow{3}{*}{ Organs } & \multicolumn{6}{|c|}{ Equivalent Dose (mSv/Gy) } \\
\hline & \multicolumn{3}{|c|}{ Calculated } & \multicolumn{3}{|c|}{ Howell } \\
\hline & $\mathrm{P}$ & $\mathrm{N}$ & Total & $\mathrm{P}$ & $\mathrm{N}$ & Total \\
\hline Bladder & 408.16 & 0.33 & 408.49 & 797.80 & 0.35 & 798.15 \\
\hline Colon & 72.46 & 0.32 & 72.78 & 67.70 & 0.23 & 67.93 \\
\hline Testes & 22.18 & 1.13 & 23.31 & 44.30 & 3.13 & 47.43 \\
\hline Liver & 0.71 & 0.17 & 0.88 & 0.53 & 0.29 & 0.82 \\
\hline Stomach & 0.63 & 0.26 & 0.89 & 0.46 & 0.13 & 0.59 \\
\hline Lungs & 0.44 & 0.14 & 0.58 & 0.28 & 0.07 & 0.35 \\
\hline Esophagus & 0.41 & 0.30 & 0.71 & 0.25 & 0.05 & 0.30 \\
\hline Thyroid & 0.18 & 0.31 & 0.49 & 0.18 & 1.86 & 2.04 \\
\hline
\end{tabular}

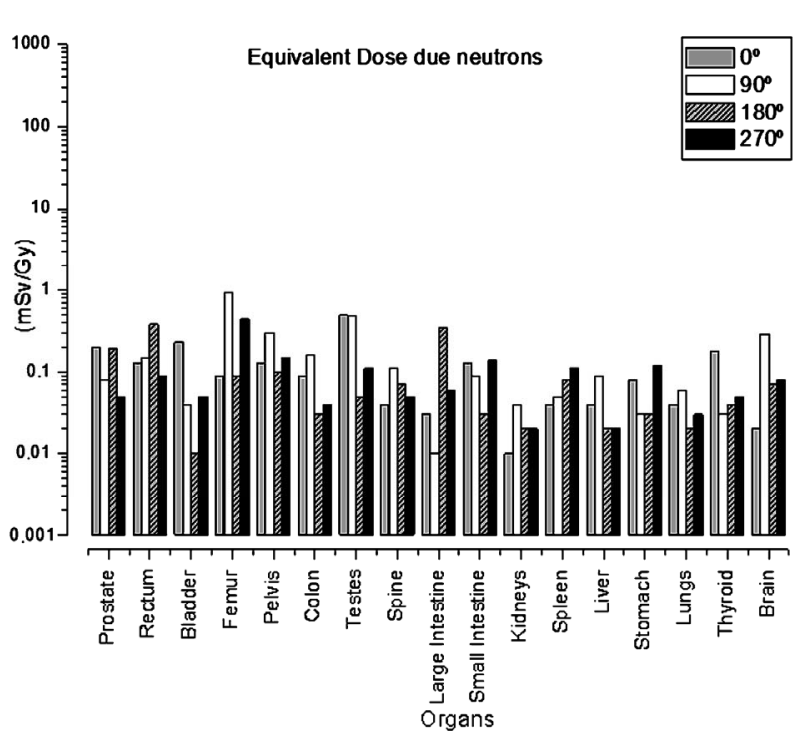

Figure 4. Equivalent dose due to neutrons calculated for each treatment angle.

\subsubsection{Effective Dose}

The results obtained from the effective dose considering the tissue weighting values described in ICRP 103 were $31.47 \mathrm{mSv}$ due to photons, while the dose due to neutrons was $0.42 \mathrm{mSv}$. Note that the effective dose due to photons is significantly higher than the effective dose due to neutrons.

\section{Conclusions}

In the present study it was verified, as already expected, that the organs close to the treatment region (rectum, bladder, femur and pelvis) present higher values of dose due to photons. It was also verified that the distributions of the values of doses deposited in the organs vary with the angle of incidence of the radiation beam. The inci-

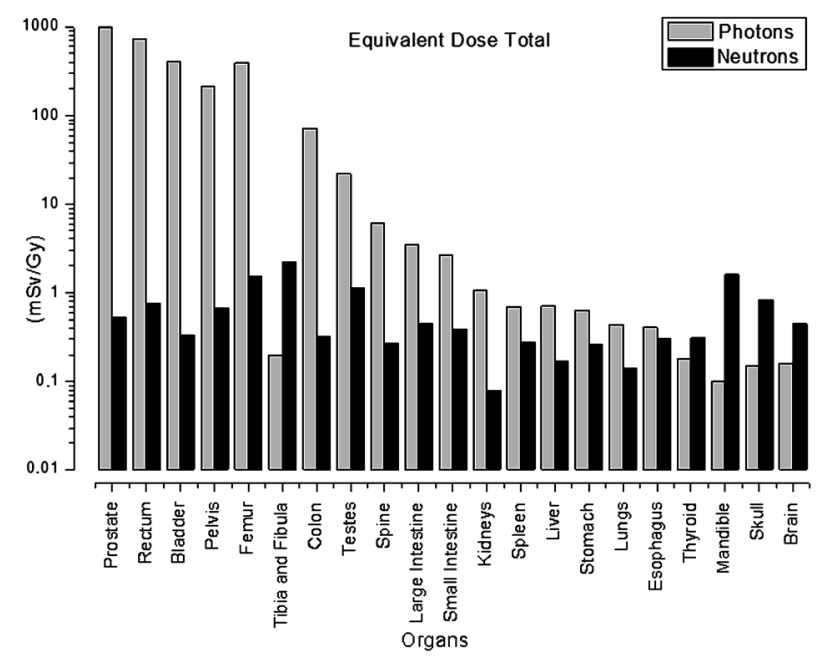

Figure 5. Comparison of some organs of the total equivalent dose due to photons and neutrons.

dence of the beam at the anteroposterior angle has the greatest impact on healthy organs adjacent to the tumor.

In this study it was also verified that both the magnitudes and the distributions of doses vary with the type of radiation. The values of doses in the healthy organ due to neutrons are significantly lower than those due to photons. As regards the distribution of the doses due to photons, it is observed that the healthy organs closer to the treatment region present higher values. With the increase in distance between the healthy organ and the treatment volume, there is a progressive decrease in the values of dose due to photons. This does not apply to neutrons, as the distribution of doses due to neutrons does not vary significantly with the increase in distance between the healthy organ and the treatment volume.

Moreover, this study also showed that MCNP is a powerful tool for the simulation of radiotherapy treatment 
for prostate cancer. Because it simulated altogether, a standard man phantom, the head of the Varian 2300CD linear accelerator, with its structural components, inserted inside a radiotherapy room, the latter with dimensions and structural components used in the real environment and the variation of the gantry tilt angle, with respective alteration of the field sizes of the therapeutic beam according to the treatment angle.

\section{Acknowledgements}

The authors wish to thank the financial support of the Conselho Nacional de Desenvolvimento Científico e Tecnológico (CNPq) and Coordenação de Aperfeiçoamento de Pessoal de Nível Superior (CAPES), Brazil.

\section{REFERENCES}

[1] World Health Organization, 2013. http://www.who.int/features/qa/15/en/index.html

[2] "Instituto Nacional de Câncer Section of prostate cancer: Estimativa de incidência de Câncer no Brasil,” 2012. http://www2.inca.gov.br/wps/wcm/connect/tiposdecancer /site/home/prostata

[3] J. Fontenot, P. Taddei, Y. Zheng, D. Mirkovic, T. Jordan and W. Newhauser, "Equivalent Dose and Effective Dose from Stray Radiation during Passively Scattered Proton Radiotherapy for Prostate Cancer," Physics in Medicine and Biology, Vol. 53, No. 6, 2008, pp. 1677-1688. doi:10.1088/0031-9155/53/6/012

[4] Y. Tao, D. Lefkopoulos, D. Ibrahima, A. Bridier, M. P. Polizzi, P. Wibault, R. Crevoisier, R. Arriagada and J. Bourhis, "Comparison of Dose Contribution to Normal Pelvic Tissues among Conventional, Conformal and Intensity-Modulated Radiotherapy Techniques in Prostate Cancer,” Acta Oncologica, Vol. 47, No. 3, 2008, pp. 442450. doi:10.1080/02841860701666055

[5] X. G. Xu, B. Bednarz and H. Paganetti, "A review of dosimetry studies on external-beam radiation treatment with respect to second cancer induction," Physics in Medicine and Biology, Vol. 53 No. 13, 2008, pp. 193241. doi:10.1088/0031-9155/53/13/R01

[6] B. Bednarz and G. X. Xu, "Monte Carlo Modeling of a 6 and $18 \mathrm{MV}$ Varian Clinac Medical Accelerator for In-Field and Out-of-Field Dose Calculations: Development and Validation," Physics in Medicine and Biology, Vol. 54, No. 4, 2009, pp. 43-57.

[7] D. J. Brenner, R. E. Curtis, E. J. Hall and E. Ron, "Second Malignancies in Prostate Carcinoma Patients after Radiotherapy Compared with Surgery Cancer," Cancer, Vol. 88, No. 2, 2000, pp. 398-406.

[8] M. W. Skwarchuk, A. Jackson, M. J. Zelefsky, E. S. Venkatraman, D. M. Cowen, S. Levegrün, C. M. Burman, Z. Fuks, S. A. Leibel and C. C. Ling, "Late Rectal Toxicity after Conformal Radiotherapy of Prostate Cancer (I): Multivariate Analysis and Dose-Response,” International Journal of Radiation Oncology, Biology, Physics, Vol. 47, No. 1, 2000, pp. 103-113.

\section{doi:10.1016/S0360-3016(99)00560-X}

[9] S. L. Tucker, R. Cheung, L. Dong, H. H. Liu, H. D. Thames, E. H. Huang, D. Kuban and R. Mohan, "DoseVolume Response Analyses of Late Rectal Bleeding after Radiotherapy for Prostate Cancer,” International Journal of Radiation Oncology, Biology, Physics, Vol. 59, No. 2, 2004, pp. 353-365. doi:10.1016/j.ijrobp.2003.12.033

[10] K. Moon, G. J. Stukenborg, J. Keim and D. Theodorescu, "Cancer Incidence after Localized Therapy for Prostate Cancer,” Cancer, Vol. 107, No. 5, 2006, pp. 991-998. doi:10.1002/cncr.22083

[11] N. Baxter, J. E. Tepper, S. B. Durham, D. A. Rothenberger and B. A. Virnig, "Increased Risk of Rectal Cancer after Prostate Radiation: A Population-Based Study," Gastroenterology, Vol. 128, No. 4, 2005, pp. 819-824. doi:10.1053/j.gastro.2004.12.038

[12] R. Kramer, J. W. Vieira, H. J. Khoury, F. R. A. Lima and D. Fuelle, "All about MAX: A Male Adult Voxel Phantom for Monte Carlo Calculations in Radiation Protection Dosimetry,” Physics in Medicine and Biology, Vol. 48, No. 10, 2003, pp. 1239-1262. doi:10.1088/0031-9155/48/10/301

[13] R. Jeraj, P. Keall and P. Ostwald, “Comparison between MCNP, EGS4, and Experiment for Clinical Electron Beams,” Physics in Medicine and Biology, Vol. 44, No. 3, 1999, pp. 705-717. doi:10.1088/0031-9155/44/3/013

[14] D. B. Pelowitz, “MCNPXTM User's Manual,” Version 2.5.0., Los Alamos National Laboratory Report, 2005.

[15] A. M. Larcher, S. M. BonetDurán and A. M. Lerner, "Dosis Ocupacional Debida a Neutrons en Aceleradores Lineales de uso Medico,” Autoridad Regulatoria Nuclear Buenos Aires, 2000.

[16] A. Facure, A. X. Silva and R. C. Falcao, "Monte Carlo Simulation of Scattered and Thermal Photoneutron Fluences inside a Radiotherapy Room. Radiation Protection Dosimetry, Vol. 123, No. 1, 2007, pp. 56-61. doi:10.1093/rpd/ncl080

[17] W. F. Rebello, A. X. Silva and A. Facure, "Multileaf Shielding Design against Neutrons Produced by Medical Linear Accelerators," Radiation Protection Dosimetry, 2008, Vol. 128, No. 2, pp. 227-233. doi:10.1093/rpd/ncm312

[18] A. J. Giordani, R. S. Dias, H. R. C. Segreto and R. A. Segreto, "Acurácia na Reprodutibilidade do Posicionamento diáRio de Pacientes Submetidos a Radioterapia Conformada (RT3D) para Câncer de próStata,” Radiologia Brasileira, Vol. 43, No. 4, 2010, pp. 236-240. doi:10.1590/S0100-39842010000400007

[19] S. C. A. Correa, E. M. Souza, A. X. Silva, H. Yoriyaz and R. T. Lopes, "AP and PA Thorax Radiographs: Dose Evaluation Using the FAX Phantom. International Journal of Low Radiation, Vol. 5, No. 3, 2008, pp. 237-255. doi:10.1504/IJLR.2008.020253

[20] S. C. A. Correa, E. M. Souza, A. X. Silva, H. Yoriyaz and R. T. Lopes, "Dose and Risk Evaluation in Thoracic Radiology Using Male and Female Voxels Phantom," International Journal of Low Radiation, Vol. 7, No. 2, 2010, pp. 81-97. doi:10.1504/IJLR.2010.032812

[21] S. C. A. Correa, J. O. Aquino, E. M. Souza and A. X. 
Silva, "Evaluation of the Dose and the Risk of Cancer Induction Associated with the Use of Transmission XRay Body Scanners Using the Monte Carlo MCNPX code,” International Journal of Low Radiation, Vol. 8, No. 5-6, 2011, pp. 340-354.

doi:10.1504/IJLR.2011.047180

[22] International Commission on Radiological Protection, "The 2007 Recommendations of the International Com- mission on Radiological Protection,” Annals of the ICRP, 2007.

[23] R. M. Howell, N. E. Hertel, Z. Wang, J. Hutchinson and G. Fullerton, "Calculation of Effective Dose from Measurements of Secondary Neutron Spectra and Scattered Photon Dose from Dynamic MLC IMRT for $6 \mathrm{MV}, 15$ MV, and $18 \mathrm{MV}$ Beam Energies,” Medical Physics, Vol. 33, No. 2, 2006, pp. 360-368. doi:10.1118/1.2140119 